\title{
ANALYSIS OF COMPLEX CHROMOSOMAL ABNORMALITIES IN A CASE OF MULTIPLE MYELOMA USING SPECTRAL KARYOTYPING
}

\section{PERUMAL GOVINDASAMY ${ }^{1}$, POOJA S KULSHRESHTHA ${ }^{2}$, PRABU PANDURANGAN ${ }^{3}$, ANIL TARIGOPULA ${ }^{1}$, JAYARAMA S KADANDALE ${ }^{2}$, CHANDRA R SAMUEL ${ }^{4 *}$}

\begin{abstract}
${ }^{1}$ Department of Centralised Molecular Diagnostics, Apollo Hospitals, Chennai - 600 006, Tamil Nadu, India. ${ }^{2}$ Centre for Human Genetics, Biotech Park, Electronic City Phase I, Bengaluru - 560 100, Karnataka, India. ${ }^{3}$ Department of Hematology, Apollo Hospitals, Chennai 600 006, Tamil Nadu, India. ${ }^{4}$ Department of Genetics, Dr. ALMPGIBMS, University of Madras, Taramani, Chennai - 600 113, Tamil Nadu,
\end{abstract}

India. Email: nchandrarsamuel@gmail.com

Received: 05 May 2018, Revised and Accepted: 05 June 2018

ABSTRACT

Objective: It was proposed to determine the chromosomal abnormalities in a 49-year-old male patient with multiple myeloma (MM) employing both conventional and advanced molecular cytogenetic techniques.

Methods: GTG-banding and spectral karyotyping (SKY) on fixed metaphases obtained from LPS-stimulated bone marrow cells and interphase fluorescence in situ hybridization (iFISH) on unsorted marrow cells were carried out to identify genetic markers of prognostic significance.

Results: The abnormal chromosomes observed through conventional cytogenetics could be resolved with SKY technique. The translocation t(4;14) (p16;q32) indicating FGFR3/IGH fusion and deletion of 13q14.3 was noticed using iFISH. The genetic abnormalities confirmed a poor prognostic outcome in the patient who died within 6 months of diagnosis.

Conclusion: This report emphasizes the need for multicolor FISH techniques besides iFISH to resolve complex abnormalities and to identify cryptic aberrations of importance in risk stratification of MM patients.

Keywords: Chromosomal abnormalities, Interphase FISH, Multiple myeloma, Spectral karyotyping

(C) 2018 The Authors. Published by Innovare Academic Sciences Pvt Ltd. This is an open access article under the CC BY license (http://creativecommons. org/licenses/by/4. 0/) DOI: http://dx.doi.org/10.22159/ajpcr.2018.v11i9.27133

\section{INTRODUCTION}

Multiple myeloma (MM) is a clinically and genetically heterogeneous hematopoietic neoplasm of plasma cells characterized by their accumulation in the bone marrow, production of excessive monoclonal immunoglobulin ( $\mathrm{M}$ or myeloma protein) in serum and urine, and osteolytic bone lesions. These features lead to pathological bone fragility, nephropathy, immunodeficiency, and hematopoietic disorders [1]. Genetic abnormalities are almost always present in MM patients although an abnormal karyotype can be detected using conventional Giemsabanding techniques in only $25-35 \%$ of them [2]. The low proliferation index of plasma cells and the poor morphology of chromosomes pose additional problems [3]. Analysis with fluorescence in situ hybridization on interphase nuclei (iFISH) using chromosome-specific alpha satellite DNA probes confirmed hyperdiploidy, locus-specific probes demonstrated microdeletions, and dual-fusion probes identified cryptic chromosomal translocations involving the immunoglobulin heavy chain (IGH) gene in $14 q 32.3$ such as t $(4 ; 14)$ [4,5]. Guidelines to perform iFISH on plasma cells selected based on morphology, immunophenotyping, or sorting are available $[3,6,7]$.

Non-random chromosome abnormalities of prognostic significance detected by iFISH help to stratify patients into two main groups - (1) the hyperdiploid MM having trisomies of odd-numbered chromosomes $3,5,7,9,11,15,19$, and 21 and (2) the non-hyperdiploid MM including translocations involving the IGH gene such as $\mathrm{t}(11 ; 14)(\mathrm{q} 13 ; \mathrm{q} 32)$, $\mathrm{t}(4 ; 14)(\mathrm{p} 16 ; \mathrm{q} 32)$, and $\mathrm{t}(14 ; 16)(\mathrm{q} 32 ; \mathrm{q} 23)$ in a majority of the cases. Monosomy $13 / \operatorname{del}(13 q)$, del(17p), and deletion of $1 p$ or amplification of $1 \mathrm{q}$ are commonly associated with aggressive disease [5]. With the advent of advanced molecular cytogenetic techniques such as multicolor fluorescence in situ hybridization (M-FISH) and spectral karyotyping (SKY) which allowed a simultaneous unequivocal identification of all the 24 chromosomes, it was possible to unambiguously characterize complex rearrangements and identify the chromosomal origin of marker chromosomes [2,8-10]. However, cytogenetic data employing these methodologies on MM are scarce because of the low mitotic activity of plasma cells, heterogeneity within the clonal population, the technical pitfalls during interpretation of results, and their restricted availability $[2,11]$. This report describes the application of SKY in the characterization of complex chromosomal abnormalities detected in a newly diagnosed MM patient.

\section{CASE REPORT}

A 49-year-old north Indian man was evaluated at the Department of Hematology, Apollo Hospitals, Chennai-6, in November 2012 for a 2 -month history of loss of appetite and severe pain in the back and legs. He was involved in agricultural pesticide business. His medical reports indicated hypercalcemia, systemic hypertension, and azotemia. He was a non-smoker and a teetotaler with no family history of cancer. Trephine biopsy section showed trabeculae of bone with intervening hypercellular marrow particles. There was a diffuse infiltration of atypical plasma cells and mitosis was increased. Immunofixation electrophoresis showed monotypic expression of the immunoglobulin A heavy and lambda light chains. Laboratory investigations revealed platelet count to be 40,000 cells/cu mm, and peripheral smear study showed intense rouleaux formation. Bone marrow cytology was particulate with blood-diluted cell trail and intense plasmacytosis (80\% plasma cells). Biochemical investigations showed serum creatinine $1.1 \mathrm{mg} / \mathrm{dL}$, calcium $15.6 \mathrm{mg} / \mathrm{dL}$, serum albumin/globulin reversal, and $\beta 2$-microglobulin $5.6 \mathrm{mg} / \mathrm{L}$. These findings were consistent with MM. He was started on dexamethasone and bortezomib along with supportive measures. Follow-up studies revealed that the patient had expired within 6 months. 
This study was approved by the institutional ethics committee. Detailed case history and bone marrow sample were collected after written informed consent was obtained from the patient. Chromosomal preparations were obtained from unsorted, lipopolysaccharide (Sigma-Aldrich)-stimulated bone marrow cells and were GTGbanded following standard protocols. About 25 metaphases were karyotyped using applied spectral imaging (ASI) systems karyotyping software (Band View version 6.0). Chromosomal anomalies were designated using standard nomenclature. SKY was performed using the same fixed chromosome preparations employing 24-color combinatorically labeled SKYPaint ${ }^{\circledR}$ Probes (ASI Inc., CA) according to manufacturer's instructions. The images were captured using an epifluorescence microscope equipped with a CCD camera. A total of 30 metaphases were analyzed and the breakpoints were determined by comparison with corresponding DAPI-banded chromosomes. The iFISH procedure was carried out on unsorted bone marrow cells fixed on slides employing seven commercially available probes for MM following manufacturer's specifications. About 300 interphase nuclei were scored for the presence of signals for each probe. Images were captured under respective filters in Olympus BX-51 microscope (Olympus, Tokyo, Japan) and analysis was done with the ASI systems software (FISH View version 6.0)

Analysis of GTG-banded metaphases showed a hyperdiploid karyotype with several abnormal chromosomes (Fig. 1a). SKY revealed these derivative chromosomes to result from complex translocations besides cryptic rearrangements in 24 of 30 metaphases (Fig. 1b)

The translocation $\mathrm{t}(4 ; 14)(\mathrm{p} 16 ; \mathrm{q} 32)$ was inferred from iFISH using IGH break apart and fibroblast growth factor receptor 3 (FGFR3)/IGH dualfusion probes (Fig. 2a-d). The probe LSI D13S319 (13q14.3) showed monoallelic deletion of 13q14.3 locus while the CEP9 probe identified trisomy 9 (Fig. 2e-f).

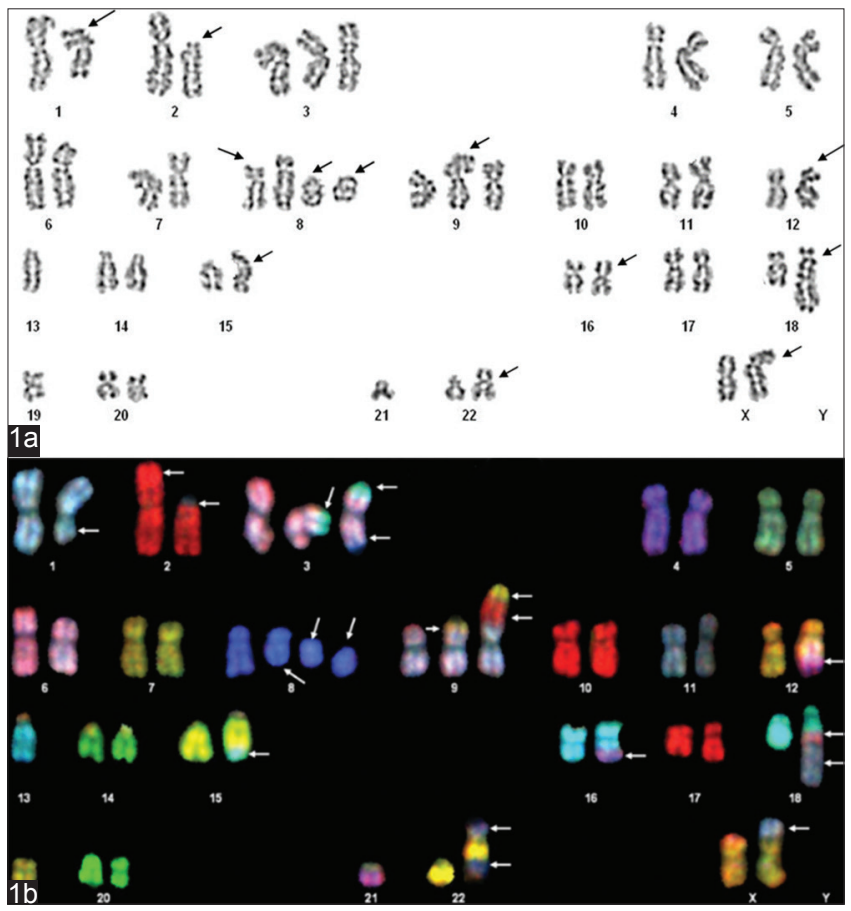

Fig. 1: (a) GTG-banded karyotype: 47,X,+der(X),-Y,del(1q), del(2) (p11),+3,del(8q),+2r(8),+der(9),der(12),-13,der(15), der(16),der(18),-19,-21,der(22) [arrows indicate abnormal chromosomes], (b) Spectral Karyotype: 47,X,+der(X)t(X;1), $-Y, \operatorname{del}(1 q), \operatorname{del}(2)(p 11), \operatorname{der}(2) t(2 p ; 17), t(3 p ; 18 q),+\operatorname{der}(3)$ $\mathrm{t}(3 ; 8 ; 18), \operatorname{del}(8 q),+2 \mathrm{r}(8), \operatorname{der}(9) \mathrm{t}(9 ; 19),+\operatorname{der}(9) \mathrm{t}(9 ; 2 ; 19)$, $\operatorname{der}(12) t(Y q ; 12 q),-13, \operatorname{der}(15) t(13 q ; 15 q), \operatorname{der}(16) t(16 q ; 21 q)$, $\operatorname{der}(18) t(18 ; ? ; 1),-19,-21, \operatorname{der}(22) t(? ; 22: ?)$
The IGH break-apart probe showed a typical pattern in $40 \%$ of nuclei scored while an extra 5' signal was seen in 35\% indicating clonal evolution. In concurrence, a classical fusion pattern and an extra fusion signal were observed in $40 \%$ and $35 \%$ of cells, respectively, with the FGFR3-IGH probe.

\section{DISCUSSION}

MM is a clonal malignancy of differentiated B-cells with acquired genetic abnormalities of clinical importance unidentifiable by conventional cytogenetic analysis. Smol and Daudignon [12] compared IGH signal patterns using FGFR3-IGH dual-color, dual-fusion translocation probe, and IGH dual-color break-apart probe in 49 patients with MM. The $\mathrm{t}(4 ; 14)$ translocation seen in $26 \%$ of cases was observed to be associated with multiple presentations of IGH, namely a loss or gain of the IGH locus and a deletion of the IGH variable segment. He et al. [13] reported several patterns of IGH deletion including monoallelic loss of whole $I G H$ locus, monoallelic deletion of $3^{\prime} I G H$ or $5^{\prime} I G H$ and biallelic deletion of 3'IGH. Further, the authors observed IGH deletions to be more frequent with $13 q$ deletion and without $t(4 ; 14)$. Our proband showed $t(4 ; 14)$ translocation along with $13 \mathrm{q}$ deletion but without IGH deletion. In addition, a gain of 5'IGH variable segment was observed in the evolving sideline. The very high association of $\operatorname{del}(13 \mathrm{q})$ abnormalities in $\mathrm{t}(4 ; 14)$ patients and not vice versa led to the suggestion that chromosome 13 abnormalities precede the translocation [11,14]. Acquisition of additional abnormalities may reflect an underlying active or genetically
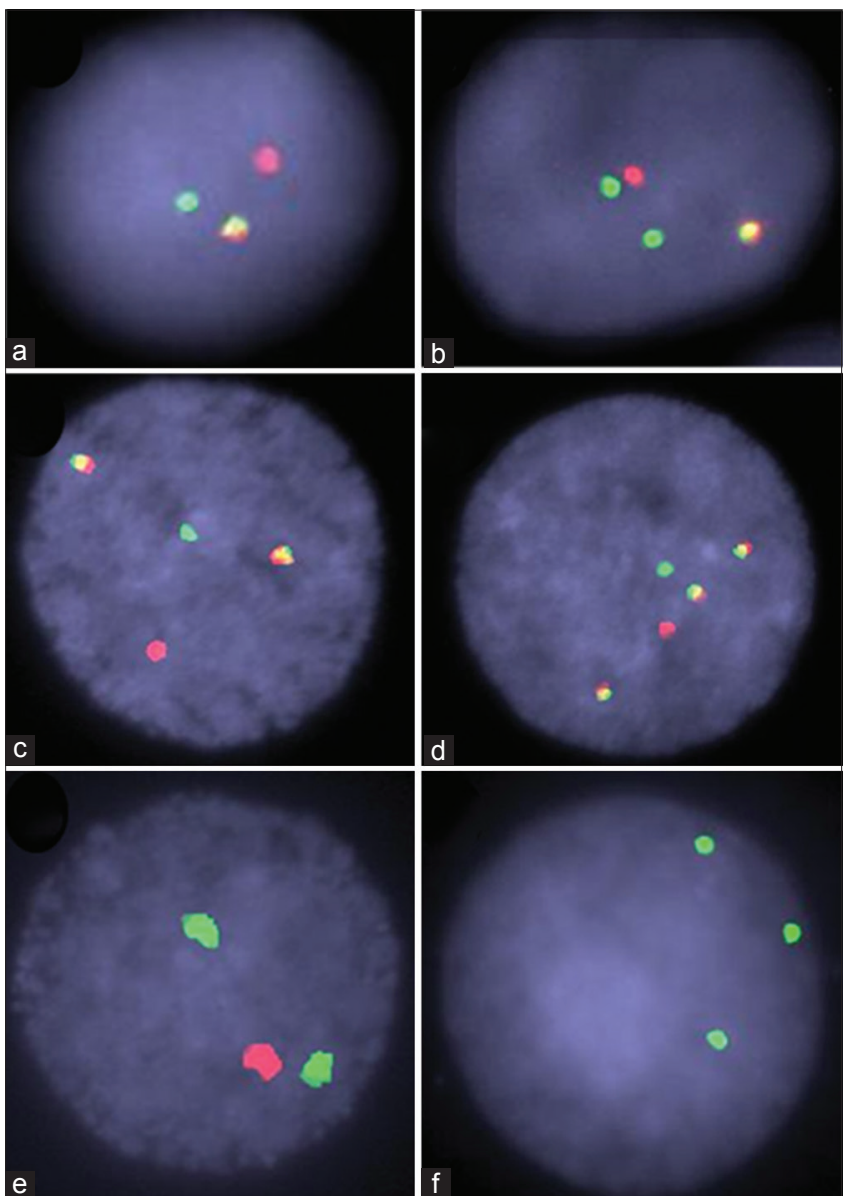

Fig. 2: Dual color IGH break-apart probe on interphase cells showing the pattern (a) F1G1R1 and (b) F1G2R1; LSI IGH-FGFR3 dual-fusion probe showing (c) F2G1R1 and (d) F3G1R1,

(e) LSI D13S19 (13q14.3)/13q34 probe showing monoallelic deletion of locus 13q14.3 (one red signal) and two copies of locus 13q34 (two green signals); (f) CEP 9 probe exhibiting trisomy 9 (3 green signals). F yellow (fusion); G green; R Red 
unstable clone driving the disease process at that point [15]. The translocation in association with del(13q) and complex chromosomal rearrangements denoted a poor prognosis in our patient who died within 6 months of diagnosis.

Application of SKY in our patient did not reveal the subtle $t(4 ; 14)$ translocation as in earlier reports describing new recurring translocations $[8,16]$. However, SKY could clarify the derivative chromosomes and confirm the numerical aberrations. Multicolor FISH techniques such as M-FISH and SKY provided improved characterization of complex and ill-defined karyotypes [2,3,8,9]. Sawyer et al. [9] using SKY identifying gain of $1 \mathrm{q}$ and loss of $8 \mathrm{p}$ frequently pointed out the importance of secondary aberrations in the progression of the disease. Several reports are available on the usefulness of SKY technique in the comprehensive analysis of chromosomes in hematopoietic disorders [17-19]. SKY will definitely serve as an adjunct to the conventional G-banding and iFISH techniques and aid in the identification of novel recurrent abnormalities in MM.

\section{CONCLUSION}

A complex karyotype denotes rapid tumor progression, and the prognostic significance of individual abnormalities will be known through extended analysis over a larger sample size on confirmation using emerging technologies such as targeted next-generation sequencing.

\section{AUTHORS' CONTRIBUTIONS}

P.G. performed the conventional cytogenetic and iFISH analyses; P.P. clinically examined, referred, and treated the patient; A.T. participated in iFISH analysis; P.S.K. and J.S.K. carried out SKY analysis; C.R.S. assisted in cytogenetic analysis; and P.G., C.R.S., and J.S.K. drafted the manuscript. All authors read and approved the manuscript.

\section{CONFLICTS OF INTEREST}

The authors declared that they have no conflicts of interest.

\section{REFERENCES}

1. Fairfield H, Falank C, Avery L, Reagan MR. Multiple myeloma in the marrow: Pathogenesis and treatments. Ann N Y Acad Sci 2016;1364:32- 51 .

2. Gutierrez NC, Camps J, Hernandez JM, Garcia JL, Prat E, Gonzalez MB, et al. Multicolor fluorescence in situ hybridization studies in multiple myeloma and monoclonal gammopathy of undetermined significance. Hematol J 2003;4:67-70.

3. Harrison CJ, Mazzullo H, Cheung KL, Gerrard G, Jalali GR, Mehta A, et al. Cytogenetics of multiple myeloma: Interpretation of fluorescence in situ hybridization results. Br J Haematol 2003;120:944-52.
4. Sawyer JR. The prognostic significance of cytogenetics and molecular profiling in multiple myeloma. Cancer Genet 2011;204:3-12.

5. Talley PJ, Chantry AD, Buckle CH. Genetics in myeloma: Genetic technologies and their application to screening approaches in myeloma. Br Med Bull 2015;113:15-30.

6. Ross FM, Avet-Loiseau H, Ameye G, Gutiérrez NC, Liebisch P, O'Connor S, et al. Report from the European myeloma network on interphase FISH in multiple myeloma and related disorders. Haematologica 2012;97:1272-77.

7. Kishimoto RK, de Freitas SL, Ratis CA, Borri D, Sitnik R, Velloso ED. Validation of interphase fluorescence in situ hybridization (iFISH) for multiple myeloma using CD138 positive cells. Rev Bras Hematol Hemoter 2016;38:113-20.

8. Rao PH, Cigudosa JC, Ning Y, Calasanz MJ, Iida S, Tagawa S, et al. Multicolor spectral karyotyping identifies new recurring breakpoints and translocations in multiple myeloma. Blood 1998;92:1743-8.

9. Sawyer JR, Lukacs JL, Thomas EL, Swanson CM, Goosen LS, Sammartino G, et al. Multicolour spectral karyotyping identifies new translocations and a recurring pathway for chromosome loss in multiple myeloma. Br J Haematol 2001;112:167-74.

10. Fett-Conte AC, Carvalho-Salles AB, Vendrame CB, Pedrassa P, Freitas PC, Varella-Garcia M. New complex chromosome abnormalities in multiple myeloma associated with a poor prognosis: A case report. Leukemia Res 2012;36:e140-2.

11. Fonseca R, Barlogie B, Bataille R, Bastard C, Bergsagel PL, Chesi M, et al. Genetics and cytogenetics of multiple myeloma: A workshop report. Cancer Res 2004;64:1546-58.

12. Smol T, Daudignon A. Comparison of IGH profile signals using $\mathrm{t}(4 ; 14)$ and IGH break-apart probes by FISH in multiple myeloma. Cytogenet Genome Res 2017;153:18-21.

13. He H, Fu W, Jiang H, Du J, Zhou L, Zhang C, et al. The clinical characteristics and prognosis of IGH deletion in multiple myeloma. Leuk Res 2015;39:515-9.

14. Nadiminti K, Zhan F, Tricot G. Cytogenetics and chromosomal abnormalities in multiple myeloma-a review. Clon Transgen 2013;2:114.

15. Binder M, Rajkumar SV, Ketterling RP, Dispenzieri A, Lacy MQ, Gertz MA, et al. Occurrence and prognostic significance of cytogenetic evolution in patients with multiple myeloma. Blood Cancer J 2016;6:e401.

16. Keats JJ, Reiman T, Maxwell CA, Taylor BJ, Larratt LM, Mant MJ, et al. In multiple myeloma, $\mathrm{t}(4 ; 14)(\mathrm{p} 16 ; \mathrm{q} 32)$ is an adverse prognostic factor irrespective of FGFR3 expression. Blood 2003;101:1520-9.

17. Nanjangud G, Rao PH, Hegde A, Teruya-Feldstein J, Donnelly G, Qin J, et al. Spectral karyotyping identifies new rearrangements, translocations, and clinical associations in diffuse large B-cell lymphoma. Blood 2002;99:2554-61.

18. Oliveira FM, Favarin MD, Calado RT, Alves AP, Godoi C, Falcao RP. Spectral karyotyping (SKY) reveals a new subset of MDS patients with clonal chromosomal abnormalities not detected by g-banding analysis. Blood 2011;118:1718.

19. Guo B, Han X, Wu Z, Da W, Zhu H. Spectral karyotyping: An unique technique for the detection of complex genomic rearrangements in leukemia. Transl Pediatr 2014;3:135-9. 